\title{
Confucian Role Ethics: Issues of Naming, Translation, and Interpretation
}

\author{
SARAH MATTICE
}

The last ten to fifteen years have seen a proliferation of philosophical manuscripts and chapters in English concerning Confucian ethics. Some of these have an overtly historical/textual approach, while others are explicitly comparative (often between Confucius 孔子 or Mencius 孟子 and Aristotle), and some seek to put ideas from the classical period into conversation with issues in contemporary ethics. Some projects begin from within a more "analytic" orientation, while still others identify themselves as belonging to the "continental" tradition. Theorists have argued that Confucian ethics is best understood as a species of deontology, as a distinctive form of virtue ethics, and as care ethics, to name a few. The project of trying to figure out the best already-present Western category to use for Confucian ethics is one that has occupied a great deal of time and effort in contemporary circles, and which may, as Stephen Angle has argued, be an example of the "unhealthy hegemony" of Western frameworks in comparative or cross-cultural philosophy. ${ }^{1}$ As I see it, the project of Confucian Role Ethics (CRE), however, is not trying to intervene in that discourse. While Roger Ames and others use 
some non-Confucian thinkers in articulating CRE, the project itself is trying to set up Confucian ethics as a distinct category of its own, on par with, but not subsumed under, other ethical traditions.

Ames opens his monograph by suggesting that CRE and its commitment to growth in personal relationships should not be understood solely as an historical artifact, but as a meaningful participant in contemporary ethical discourse. In the Introduction to Confucian Role Ethics: A Vocabulary Ames writes:

The contention of this monograph then, is that we are entering upon a transitional period of enormous proportions with the imminent emergence of a new cultural order, and that Confucianism offers us philosophical assets that can be resourced and applied to serve not only the renaissance of a revitalized Chinese culture, but also the interests of world culture more broadly. ${ }^{2}$

That is, Ames is arguing for what Kam-Por Yu, Julia Tao, and Philip J. Ivanhoe have called taking Confucian ethics seriously-this means that one does not "see it simply as something East Asian or Confucian; to take Confucian ethics seriously is to be concerned with the contemporary philosophical relevance of the Confucian tradition."3 CRE adds to this that taking Confucian ethics seriously in a philosophical sense also requires taking it first and foremost on its own terms, which requires rethinking and retranslating much of the content of early Confucian texts, as their early reception in the western world was filtered through some decidedly distortive sources. While Ames may be the most famous current proponent of Confucian Role Ethics, this interpretation of Confucianism is situated in an intellectual lineage that owes much to earlier interpreters such as Zhang Dongsun 張東蓀 (18861973) and Tang Junyi 唐君毅 (1909-78), and which continues in the work of scholars such as Henry Rosemont, Jr., A.T. Nuyen, WEN Haiming, John Ramsey, and others. ${ }^{4}$

Many contemporary accounts of Confucian ethics focus heavily on the classical texts, especially the Analects 論語 and the Mengzi 孟子, although some do include and/or focus on other texts. Most accounts share certain features such as the central place of the family and the importance of relationships, the need for a strong connection to and contribution to tradition, an understanding of ethical life as inherently political, and the demonstration of ethical cultivation through ritual proficiency, to name a few. CRE also shares these features, but it takes them in what I call elsewhere a "radically relational direction," putting correlative cosmology and relational personhood at the nexus of the interpretive framework. ${ }^{5}$ 
When we speak of a ethic(s), an $\mathrm{X}$ ethics, we take that to be a theory of ethics that focuses on $\mathrm{X}$, takes $\mathrm{X}$ as a central concept or concern. Confucian Role Ethics, then, is an account of ethics drawn from Confucian traditions that takes human persons as irreducibly relational and human lives as flourishing in and through familial, social, and political roles. ${ }^{6}$ Ames writes, "At the very heart of Confucian role ethics, distinguishing it fundamentally from more familiar Western ethical 'theories,' is a concept of a relationally constituted person who realizes a vision of the consummate life through a kind of moral artistry."

I see at least three sets of concerns that animate the reasoning behind Confucian role ethics: naming, translation, and interpretation. In terms of naming, I discuss this project as an example of zhengming 正名, or proper naming, which is a common Confucian ethical project. Confucian thinkers are often preoccupied with appropriate categorization, one species of which is naming. The naming of Confucian ethics as role ethics, I argue, is not only consistent with but is situated in a larger Confucian concern with appropriate names. In terms of translation, I explore CRE in conversation with the translation theory of Lawrence Venuti, who argues against translations of "fluency" for an anti-domestication strategy-a method for translations to maintain some level of "foreignness." Finally, I engage certain hermeneutic and interpretive assumptions about the very project of coming to understand "Confucian" ethics at all. In doing so, I also provide certain critical reflections on "role ethics" as a way of understanding Confucianism.

\section{NAMING}

In Confucian traditions, names matter. One way to understand the project of Confucian role ethics is as an example of zhengming 正名, or proper naming, which is a common Confucian ethical project, and an inherently political project. Confucian thinkers are often preoccupied with language and appropriate categorization, one species of which is naming.

While the phrase zhengming itself only appears once in the Analects (although proper naming is a concern of other passages), and not at all in the Mengzi, it is the subject of an entire chapter of the Xunzi, and is incorporated into Confucian concerns as the tradition moves forward. The most oftencited passages in the Analects having to do with proper naming are 12.11, 13.3, and 13.6, although as nearly every commentator on early Confucianism remarks, the key terms "ren" and " $l$ " (along with others) are in a constant process of definition and refining, as Confucius takes these terms up in new and innovatively philosophical directions-so the concern with naming roles, relationships, and ideals is present through much of the text. In addition, the 
context of the text, and of early Confucianism, as a product of the situations of the pre-Qin Warring States period, suggest that the name of a person or a role is especially important for what that person is expected to do and how that person is expected to behave.

In 12.11, when asked by the Duke of Qi about zheng 政, effective governing, Confucius replies: “君君, 臣臣, 父父, 子子。” In his reply, Confucius uses the reduplicative function of nouns to emphasize the already present moral dimension of the roles of ruler, minister, father, and child. In saying that the ruler should rule, the minister minister, the father father, and the child child, he directs the Duke's attention to the fact that these key political and family roles and relationships are inherently normative, and as such require regular tuneups to be attuned properly. To be appropriately called a ruler, certain practices, attitudes, activities, and behaviors are expected, and one who does not act/live in accordance with these should not be called a ruler. The tuning standard for Confucius was the flourishing of the Zhou Dynasty, but his project, as I argue elsewhere, is not simply retrospective: "it is an hermeneutic process of attuning names, of proper naming, intersecting past meanings, present circumstances, and future possibilities." That is, although for Confucius the standard was the Zhou, we need not understand zhengming as limited to the Zhou specifically, but we can see the activity of proper naming as responding to effective configurations, as Confucius understood the Zhou to be.

In 13.3, we see Confucius claim that his first priority of state leadership would be zhengming. Although Zilu is concerned that this would be impractical, Confucius argues that this is, in fact, the lynchpin of ethicopolitical success, upon which speech, matters of state, ritual proficiency, the playing of music, the application of standards, laws, and punishments, and the understanding of the people's daily purpose depend. ${ }^{10}$ I have argued elsewhere that the naming of Confucian ethics as role ethics is an instance of zhengming, of the project of attuning names.

Thus, the naming of Confucian ethics as "role ethics" points to the three directional movements of the process of zhengming. First, in attempting to be as faithful as possible to the tradition itself, it is incorporating past meanings and insights, while being sensitive to the often unconscious foisting of prejudices onto another tradition. Second, it recognizes the current philosophical landscape and, in seeking to properly contextualize Confucian ethics, negotiates with contemporary scholarship. Finally, it is not solely a scholarly move. Rosemont and Ames find insights in this tradition that have applicability now and for aiding in the process of intelligent deliberation regarding future possibilities. As such, Confucian role ethics is itself an instance of zhengming. ${ }^{11}$ 
The naming of Confucian ethics as role ethics, I argue, is not only consistent with but is situated in a larger Confucian concern with appropriate names. Names, in Classical Confucianism, are understood as real, important, useful, efficacious, but also as provisional, temporary, adjustable, and negotiable. Because naming is not merely a descriptive act, but an inherently normative one, the negotiation of names also carries with it a negotiation of both activity and expectation. Calling Confucian ethics "role ethics" implies a particular set of practices and a particular set of expectations, and these particulars are different from other ways of naming Confucian ethics.

In Confucian Role Ethics: A Vocabulary, Ames argues that family is understood as the governing metaphor in Confucianism. Playing with the term lun 倫, Ames describes lun (human roles, living one's roles and relations) as part of a cluster of cognate "lun's," the intersections of which are helpful for making sense of the radial order made possible through and demonstrated in family relations. He writes:

When we bring these various associations of this family of characters together, the insight gleaned is that the perceived source of growing proper "relations" is fundamentally discursive: an aggregating 'relating to' and "giving an account of oneself" within the compass of one's roles that define family, and by extension, community. Simply put, a thriving familybased community derives from continuing familial patterns of effective communicating [. . .] Family roles as a strategy for getting the most out of relations are thus an inspiration for order more broadly construed—social, political, and cosmic order. We might say that Confucianism is nothing more than a sustained attempt "to family" the lived human experience. For Confucianism, it is through discursive living in a communicating family and community that we are able to enchant the ordinary, to ritualize the routine, to invigorate the familiar, to inspire the customary habits of life, and ultimately, to commune spiritually in the common and the everyday. ${ }^{12}$

In naming Confucian ethics as role ethics, then, the "role" not only brings in connotations from the Chinese terminology, but from the kinds of concerns that animate this interpretation. Roles are the radial center of this vision of prescriptive ethics, from which all activities and concerns both begin and come to completion. It also acts as a kind of categorizationnaming, in Classical Chinese, is less connected with a kind of vertical concept subsumption than with a more horizontal project of categorization-and the naming of Confucian ethics as role ethics marks out a distinct category in the larger field of ethics. 


\section{TRANSLATING}

As not simply a descriptive move, the normative side of naming Confucian ethics as role ethics concerns activity and expectation-how do we understand the key features of personal, familial, and political cultivation in a Confucian context? The re-naming thus entails re-translating and re-articulating with the same intersection of past, present, and future.

One of the consistent criticisms Ames especially has received from others in the sinological/philosophical community has been in the form of concerns about translation. This is a long-standing issue, and is not limited to his work on CRE. However, as a central component of the work in CRE has to do with translation, thinking about some of the second-order issues with translation seems appropriate.

One of the consistent features of Ames' work is a concern with translation that does not replace the ambient assumptions and background cosmology of classical China with either broadly western/Abrahamic or contemporary frameworks. This often requires extended discussions of metaphysics (or what Ames and Zhang call "cosmology"13) in the context of parsing certain translations. It also often requires stretching the bounds of common English in ways that visibly depart from more traditional translations-think here of the difference between "benevolence" and "consummate personhood" as translations for ren 仁.

While Ames explains this in terms of attention to the original language, context, and commentaries, I would like to suggest an additional way of thinking about the value of efforts to translate, and so to interpret, that may go against the grain of the target language or audience. In Lawrence Venuti's book, The Translator's Invisibility, he critically examines translation practices (into English) from the seventeenth century to today. He demonstrates that fluency, often taken for granted as an obviously desirable translation strategy, is in fact one of many strategies, and he shows how it was that fluency came to be prized over other translation strategies in English. He does this in the context of arguing that certain ethnocentric and culturally imperialistic values are imposed on foreign texts during the process of translating for "fluency." In this section, I explore the idea of understanding Confucian role ethics as a translation project, as what Venuti calls "resistancy", or "foreignizing translation." 14

Venuti begins his project by thinking through his title phrase, the invisibility of the translator. By prioritizing fluency in terms of translation, the translator has become "invisible" in two ways; first she is invisible in terms of her manipulation of English, and second, the fact of her translation is made invisible through what Venuti calls the "illusion of transparency," where the translation gives the effect of reading the original: 
The illusion of transparency is an effect of fluent discourse, of the translator's effort to insure easy readability by adhering to current usage, maintaining continuous syntax, fixing a precise meaning. What is so remarkable here is that this illusory effect conceals the numerous conditions under which the translation is made, starting with the translator's crucial intervention in the foreign text. The more fluent the translation, the more invisible the translator, and, presumably, the more visible the writer or meaning of the foreign text. ${ }^{15}$

This is the translation strategy Venuti calls "familiarizing" or "domesticating," where the goal of the translation is to make the text seem as if it were written in the target language. By making her work seem invisible, the translator is giving the illusion of direct access to the author(s) of the original text. If it reads "fluently" in this sense, the translation seems natural, and so less obviously a translation. This, according to Venuti, has been the governing standard of translation into English for the last several hundred years. ${ }^{16}$

However, Venuti argues that this practice is at best naïve and at worst "symptomatic of a complacency in Anglo-American relations with cultural others, a complacency that can be described-without too much exaggerationas imperialistic abroad and xenophobic at home." ${ }^{17}$ That is, by making something written in classical Chinese seem too at ease in contemporary American English, it not only suggests that "our" language is the language of the world, but also that nothing else is really terribly different from how "we" think.

Venuti draws on an 1813 lecture by Friedrich Schleiermacher, in which he argues that there are primarily two methods of translation-a domesticating method that is inherently ethnocentric and reduces the foreign text to target language cultural values, and a foreignizing method, "an ethnodeviant pressure on those values to register the linguistic and cultural difference of the foreign text, sending the reader abroad"-and that the choice of which to use is ethically significant. Schleiermacher argues for the foreignizing method, and others since have argued that the translated text should be a place where the cultural other is allowed to manifest, although always through the medium of the target language. ${ }^{18}$ Venuti takes this up as a call for using translation to disrupt and resist target language cultural values and codes. "In its effort to do right abroad, this translation method must do wrong at home, deviating enough from native norms to stage an alien reading experience-choosing to translate a foreign text excluded by domestic literary canons, for instance, or using a marginal discourse to translate it."19 This, he argues, is not a simple valorization of the foreign as foreign, but a strategic move against ethnocentrism, racism, cultural imperialism, and 
narcissism. The goal, then, is a political goal, to develop translation practices that signify the genuine difference of the foreign text, while still maintaining the possibility of real inter-cultural understanding-that is, this goal is political, but in service of, and indeed perhaps required for, a more genuine understanding of the other.

This strategy of resistancy or foreignizing is not immune from the troubles that plague other translations-it too is committed to a particular interpretation of and orientation toward the text-but translators who employ this kind of strategy tend to be more upfront with their partiality. The very idea of resisting invisibility and fluency as translation values requires a somewhat more elaborate explanatory framework and explicitness about the project of translation on the part of the translator. But, choosing this kind of method enacts the text as what Venuti calls "a locus of difference, instead of the homogeneity that widely characterizes it today." 20

There are several ways that I see the project of Confucian role ethics as using this kind of resistant or foreignizing methodology. First, the charge given by Venuti-to read and write translated texts in ways that recognize and valorize linguistic and cultural difference-is at least parallel to the overarching concern of CRE as an interpretive project attempting to let the Chinese tradition speak for itself. ${ }^{21}$ Henry Rosemont Jr. writes of the project of Confucian role ethics that it is part of a larger project attempting to ask the question, what makes Chinese thought Chinese? and "what is the cluster of concepts within the early Chinese canons that on their own terms give full expression to this notion of Confucian role Ethics"?22 That is, how can we understand Chinese philosophy broadly, and ethics more specifically, in the distinctively Chinese ways that it has emerged. This requires active strategies to resist asymmetrical reductionism. Ames and Rosemont here follow Zhang in giving explicit attention to the differences between Chinese and English (or Western languages more broadly), not only in terms of vocabulary but in the ways in which grammatical structures and metaphysical concerns are coinfluencing.

Second, while many contemporary interpreters of Confucianism broadly and Confucian ethics in particular will draw on traditionally accepted translations for key terms, even while sometimes acknowledging certain problems or issues with them, CRE is explicit about the connection between interpretation and translation such that regardless of the general acceptability of a given term for translation, if it carries a problematic interpretive connotation, it requires reworking. Ames' recent monograph has many examples of this, including retranslations and extensive discussions of key terms, for example xing 性 (commonly translated as human nature, there translated as natural human tendencies). ${ }^{23}$ 
Third, Venuti notes that a translation that values resistancy and foreignizing methods tends to "value experimentation, tampers with usage, and seeks to match the polyvalencies or plurivocities or expressive stresses of the original by producing its own. ${ }^{24}$ These three characteristics are certainly present in CRE. Consider here the descriptions of ren as a kind of moral artistry and the use of the language of aesthetics in making sense of ethics. ${ }^{25}$ This is in part a way of experimenting, altering common usage, and producing parallel kinds of expressions to make good sense of the original in the new language and context.

Finally, the concern that motivates much of Venuti's project is a concern with cultural imperialism and ethnocentricism, and the ways in which those are produced and reproduced through projects of translation. This concern is visibly present in the interpretive framework of CRE as attempting to carve out a space for Confucian ethics alongside other ethical theories, rather than subsumed under a western theory. ${ }^{26}$ All translations and interpretations are products of a particular context, and that context is purposeful. Part of the judgment of the value of a given translation/interpretation needs to concern how well it matches with its contextual purpose. ${ }^{27}$ So, part of thinking through how to make sense of Confucian ethics, and how to translate given terms and phrases, needs to involve the more meta-questions of context, purpose, and audience.

\section{INTERPRETING}

Translation and interpretation are inseparable. There is no translation into a bare, uninterpreted space, and no interpretation from another language that does not privilege certain translations over others. Hans-Georg Gadamer, the twentieth century giant of hermeneutics, once famously argued that one of the serious problems we face, coming out of Enlightenment thinking, is that we have a real prejudice against prejudices. As Jean Grondin explains: "Gadamer is so reluctant to renounce the ideal of a critical elucidation of prejudices that he himself criticizes a Cartesian prejudice: the prejudice against prejudices! The expression, ingenious, presupposes that there are prejudices prejudicial to the understanding and that the prejudices against prejudices is part of it." ${ }^{28}$

That is, we tend to think that there is a way to understand something without having any preconceptions, expectations, or anticipations. From an hermeneutic perspective, this is impossible. Whether it be language, culture, history, time, location, society, personal idiosyncrasies, or some combination thereof, we all begin engagements of understanding within a landscape and a horizon of our own. The interpretive challenge, then, is not to get ourselves 
into outer space, as it were, but to attempt to carefully refine the prejudices we do have so as to be the most responsible to the tradition in question as possible.

The interpretive methodology of Confucian role ethics begins from this sort of hermeneutic perspective. Given that unfettered access is at best an illusion and at worst a dangerous distortion, a primary component of Confucian ethics is attempting to articulate the relevant ambient cultural assumptions at work in the formative period of Confucianism. ${ }^{29}$ This work was started in large part by twentieth century comparativist Zhang Dongsun, whose pioneering work in comparative epistemology and cultural philosophy locates many of these discussions in his attempts to articulate his own cultural, linguistic, and philosophical heritage, in light of increasing dominance of western concepts. ${ }^{30}$ That is, the over-arching concern with ambient cultural assumptions is one that is located in a concern with accuracy and precision in interpretation-what is required to give the best possible account of the tradition on its own terms in another language and cultural context? ${ }^{31}$

As I see it, Confucian role ethics operates with (at least) eight interconnected interpretive techniques:

1. Attend to language, cultural evidence, and texts and commentaries from related fields (such as the Yijing 易經, the early medical texts, etc.) to articulate cultural assumptions, especially those that differ from contemporary Western ones.

In specific terms, for CRE this means a focus on correlative or $q i$ 氣 cosmology. ${ }^{32}$ When taken to the level of persons, correlative cosmology entails the idea of relational personhood, where personal identity is understood first and foremost as relationally constituted. ${ }^{33}$ CRE also argues, in this vein, that the processual nature of Classical Chinese language and the immanent cosmology (not metaphysics) lends itself to being understood as lacking certain common dualisms present in the west such as mind/body, reason/emotion, God/man, human/nature, and so on. Many CRE interpreters have also argued, following Zhang and Ames, against the idea of a strong notion of philosophical transcendence in early China. ${ }^{34}$

2. Highlight relevant differences.

Beginning with Zhang Dongsun and continuing through other twentieth century figures such as A.C. Graham, CRE takes difference, and especially differences between cultures, to be a central interpretive concern. One difference often highlighted by Ames and others is cosmological: "There can be no superordinate and independent 'one' in this ecological cosmology, 
no single cause, no grounding, foundational standard, no one privileged order." ${ }^{35}$ Any interpretive strategy has to identify the appropriate audience, and given that audience, figure out what to emphasize. In this case, since the audience is primarily a contemporary audience (although not an exclusively Western audience), given the tendencies toward reductionism and asymmetry present in the field, setting a context where genuine differences are identified not only helps to avoid reductionism and asymmetry, but allows for Confucianism to make more of a distinctive contribution to the field. ${ }^{36}$ This is contrasted, for instance, with the interpretive strategy found in William de Bary's book, Confucian Tradition and Global Education (2007), where he suggests that students, in order to generate interest, should read Chinese classics and look for what is familiar first. Although an interpretation can focus too much on difference, and head its readers toward incommensurability, CRE attempts to avoid that problem through explicit concerns with comparison.

3. Use careful generalizations and retail analogies.

Many contemporary comparativists and non-Western philosophers have argued for the need for careful generalizations across different traditions. Chenyang Li calls these "cultural patterns" and suggests that as long as they are used provisionally, carefully, and with appropriate context, they are crucial in contemporary philosophizing. ${ }^{37}$ Cultural patterns are probabilistic, not universal, and not only admit of exceptions but also admit of change over time. He further suggests that the presence of cultural patterns makes generalizations necessary, but that the fact of needing generalizations does not privilege any one interpretation over another. Ames describes these as informed generalizations, and argues at length that they are a necessary part of doing comparative work. ${ }^{38}$ Furthermore, he argues that we need to use retail (as opposed to wholesale) analogies in order to create temporary bridges between ideas. ${ }^{39}$

4. Draw on a wide variety of sources.

CRE thinkers often draw on a wide variety of sources, from more traditional early commentaries in China to twentieth-century Chinese intellectuals, from American pragmatists to Chinese sociologists. This catholic resourcing is somewhat unusual, but it provides a number of different avenues of approach to the material, many of which are being drawn from Chinese sources. This is important, because as Aaron Creller has noted, we have a responsibility to try to "de-orientalize" our perspectives, and one of the ways to do this is to look for "local" interpretive bridges to play a more central role. ${ }^{40}$ So, for instance, looking to a twentieth century Chinese philosopher 
such as Zhang Dongsun as a bridge person between classical China and the contemporary West not only provides valuable insights but also helps to correct against the tendency for Western sources to occupy the center. Or, looking at classical medical treatises might give insight into how early Chinese philosophers were understanding the body, which may provide insight into practices of ethical cultivation.

5. Re-orient readers by retranslating terms and providing extensive glossaries and explanations of vocabulary.

As discussed earlier, translation and interpretation are deeply intertwined, and interpretation needs to be sensitive to issues of translation. As most are aware, many common translations of Chinese philosophical terms were first coined by Jesuit missionaries. These missionaries were often high caliber scholars doing revolutionary work, often with the aid of Chinese scholars who have received little historical credit for their contributions. However, their work was in the context of conversion, and that context colors many of their translations. In addition, just because a term has inertia as a translation, or is in the Mandarin/English dictionary, does not make it the best philosophical translation. While translations do need to be anchored in the original text, bringing attention to how we use words and what they mean is an important interpretive project.

6. Attempt to draw out what is distinctly Chinese, but not impossibly foreign. As mentioned earlier, CRE interpreters tend to begin an interpretation with an emphasis on difference. This emphasis on difference can sometimes go too far and lead to issues of incommensurability. However, it can also go too far in the other direction, and lead to problems of relativism. Being able to make cultural generalizations does not entail relativism, but rather a kind of cultural pluralism. Paying attention to what is distinctly Chinese does not imply either that there are no standards that can be shared across traditions or that the distinctive features apply only and ever to Chinese people. The project of CRE is committed to taking Confucian ethics seriously, meaning that this interpretation sees Confucianism as having genuine contributions to make to a world conversation about how to live well. Ames writes, "I would contend that it is precisely the recognition and appreciation of the degree of difference obtaining among cultures in living and thinking that properly motivates cultural translation in the first place, and that ultimately rewards the effort." ${ }^{41}$ That is, we are not presented with only two options, universalism or relativism. We have a middle ground that recognizes the value of difference in the context of seeking understanding and wisdom in how to live here and now. 


\section{Highlight the political.}

It is especially with respect to this interpretive tool that CRE can be seen as doing something different from some contemporary projects that look to Confucian ethics as a species of Virtue Ethics, or Care Ethics, or Deontology. Paying explicit attention to the political dimensions of and context for an interpretation is a central concern of CRE. This, however, does not detract from the quality of the interpretation. Just as Berthold Brecht once remarked that the only non-political art is the art of the ruling class, so too the only "non-political" interpretation is one that is already situated in a place of interpretive power, which in this case is likely the Western canon.

As this is an interpretive tool, it also has specific standards with it that do not entail this being the only interpretation that is explicitly political. For instance, Bryan Van Norden's interpretation of Confucianism as Virtue Ethics in Virtue Ethics and Consequentialism in Early Chinese Philosophy is a good example of a careful interpretation that is explicitly trying to deal with problems of ethnocentrism. Yong Huang's recent book, Why be Moral: Learning from the Neo-Confucian Cheng Brothers, is also explicitly political, but in a different direction, aiming at getting the attention of mainstream western (analytic) philosophers. CRE is not the only political interpretation of Confucian ethics, but it does take this political dimension to be relevant, especially in meta-concerns of interpretation and translation.

8. Give as genuine and accurate an account as possible.

That is, while Ames in particular is often described as doing what Stalnaker calls "creative, emblematic generalization" or what Kwong-loi Shun calls "philosophical construction," both of which imply some sense of movement away from the classical texts and toward the personage of the interpreter, CRE is attempting to give a genuine and accurate account of how we might understand Confucian ethics today. ${ }^{42}$ This is a philosophical project, and not in some sense an historical project, so the emphasis is not on how Confucianism worked out as a political ideology in the Han, for instance, but nonetheless it does not seem to understand itself as departing from the tradition. It tends to employ the common Confucian hermeneutic strategy of "return to the classics" and through commentary be original and contribute to the lineage. This is a strategy at play in most later Confucian scholars.

The contrast here might be with something like Kupperman's Character Ethics, which owes a significant debt to Confucianism but is not in particular claiming to be a species of Confucian ethics. This is unlike Peimin Ni's Gongfu Ethics, which like Confucian role ethics is trying to carve out its own space in contemporary ethical discourse as a distinctly Chinese/Confucian 
ethical project. CRE, then, is not trying to articulate a view inspired by Confucianism, but rather is giving an articulation of Confucianism.

\section{CONCLUSION}

I would like to conclude with some critical and hopefully constructive remarks about Confucian role ethics. There are some critical engagements with CRE that have already been well raised. Ames himself brings up several critical concerns in the epilogue to the monograph; he considers problems like justice, impartiality, and corruption, and the need for something like regulative ideas in CRE. I have elsewhere argued that CRE could benefit from a more robust feminist orientation, and Stephen Angle raised interesting questions about the normative force of role ethics and the grounding of commitments to interdependence and relationality in his 2014 chapter on the Analects. In a book symposium in Frontiers of Philosophy in China, scholars critiqued Ames' monograph and CRE along a number of different avenues, from May Sim's engagement with his translation and parsing of ren to Daniel Bell's questions about the nature of community in role ethics, from WEN Haiming's concern with connotations of "role" ethics in contemporary Chinese language to ZHANG Xianglong's issues with Ames' discussion of xiao. While there are many interesting critical avenues to pursue, as this chapter has mainly focused not on detail issues with particular translations or interpretations, but with bigger picture questions, that is where I will conclude.

By far the most common critical perspective on CRE has come from other interpreters who are interested in Confucian Virtue Ethics. While critiques may be implicit or explicit, a focus on virtue is often seen as suggesting that a focus on role is incorrect, and vice versa. I actually do not find this to be particularly compelling-often discussions of Confucian Virtue Ethics do much to enhance and complicate virtue ethics, and in some cases the vocabulary of virtue can be useful for thinking through Confucianism, especially with regards to particular thinkers or passages. These interpretations are not aimed at the same goal, and so do not need, in particular, to be in conflict. That said, Ames and others are also occasionally critical of the idea of Confucian Virtue Ethics, as tending to reduce notions of self and principles to western ideas in ways that they find contrary to the early Confucian texts.

One common complaint about CRE is that role ethics is, in fact, already a present category in Western ethics. Some discussions of business or other professional ethics have used the term "role" to describe the particular obligations one might have as a doctor, for instance, that do not apply outside of that role. As a central part of the argument for this interpretation 
is that it is trying to take Confucian ethics on its own terms, and on equal footing with other Western and non-Western ethical theories, the fact that something called role ethics already exists would seem to be a serious issue. However, I think there are a couple of reasons why this is not that big of a problem. First, the argument is not that Confucian ethics is a species of professional ethics, but that "role" is a useful term for the emphasis of Confucian ethics. If we were prevented from ever using any terms already used, philosophical discourse would be brief indeed. Second, although the term does exist in Western ethics, that does not mean it necessarily has priority in determining how the category will be used moving forward. Finally, there are several serious differences between Confucian role ethics and role ethics as found in professional ethics. The role ethics found in professional ethics does not constitute its own theory, but tends to rely on a theoretical framework from a more established position (virtue, utility, deontology, etc.) to resolve its problems. So, while "role ethics" may mark out a specific discourse, it is not the same discourse nor is it operating on the same theoretical level as CRE.

Ames in particular is also occasionally accused of being "post-modern," where the context makes it clear that this is a bad thing. I think when this is used, critics are concerned that there is not a tight enough relationship between theory and text. Whether or not that is a fair concern is a topic for another day. I would actually suggest that in as much as Ames and other CRE interpreters are post-modern, they are perhaps not post-modern enough, and could go further to incorporate post-colonial, feminist, and other postmodern insights into the interpretive frame. Given the concern with foreignizing translation, for example, why are we still saying "ethics" and "Confucius" and not using the Chinese? Why translate at all? For instance, if a major concern is setting up the conditions for the tradition to speak on its own terms, why not attempt to "properly name" Confucian role ethics 儒家角色倫理學 (rujia juese lunlixue), and attune the ears of English speakers to the Chinese? Or at least drop the "Confucian" and call it "Ruist" role ethics, as some scholars have already done? Or why include the "role," and not just call it Confucian/Ruist ethics?

I think the answer to this is not only an answer provided by Confucian role ethics, but by most contemporary engagements, be they through virtue ethics, care ethics, or another name. Part of the process of zhengming entails attention to the circumstances surrounding the present moment, and the circumstances of the present moment are encouraging a conversation involving Chinese philosophy generally and Confucian ethics specifically, in the English-speaking philosophical world. This is a purely pragmatic concern, and one that many hope will fade as mainstream English language philosophy 
becomes less Eurocentric. Calling Confucius "Kongzi," for instance, is a small change, but one that does help to circumvent certain problematic historical issues. The trouble is that non-specialists who are familiar at all with Confucius do not recognize "Kongzi." So, this is a strategy that will take time and effort on the part of specialists to educate non-specialists.

However, this actually presents another concern. Even if mainstream English language philosophers were willing, able, and sensitized to Chinese language, the phrase for "ethics" in Chinese is not historically how Confucian thinkers would have understood their projects. In Mandarin Chinese, “ethics," in the technical sense used by philosophers, is lunlixue 伦理学. This phrase is one of many contemporary Chinese phrases borrowed from the Japanese, who created an entire lexicon of vocabulary during the Meiji Restoration, in an attempt to translate foreign technical terms into Japanese.

So even if one is concerned to use terms and categories internal to the tradition as resistance to Western imposition and centralization, as contemporary theorists such as Leah Kalmanson argue for, just borrowing the current Mandarin term is not enough. ${ }^{43}$ We have to dig into why the Meiji-era thinkers found lunlixue to be a good translation for ethics, and why contemporary Chinese speakers have continued to find this term appropriate. As something like "the study of the patterns and reasons of human relationships," lunlixue has some overlap with contemporary connotations of "ethics," and some genuine differences. One of the things it does is foreground this importance of human roles and relationships (lun). If, as Ames and others suggest, a Confucian conception of ethics takes a different direction than common western ethical theories, then naming Confucian ethics something that highlights this overlap, but also gives attention to a central difference, makes sense. We can do more with this by bringing concepts, ideas, and vocabulary from traditions like Confucianism (Ruism) into contemporary western discourse, so that we can, for instance, ask after a Socratic li 禮, a Cartesian xin 心, or Iris Murdoch's account of xiao 孝. In a sense, this is a complement to the foreignizing translation strategy-not only to choose less familiar translations or leave fewer terms untranslated and require extensive glosses, but to de-center the field by advocating a plurality of vocabulary.

Finally, I would like to end by suggesting that CRE is not the end of the discussion. CRE is an heuristic category, a provisional and useful way of approaching and engaging Confucian ethics in the current philosophical landscape. Saying that CRE is valuable does not entail that thinking about Confucian ethics in terms of virtue or care is not useful, or that Confucianism does not have something particularly valuable to contribute to those conversations. But, contributing to those conversations and carving out a 
space for itself are different projects, and require different discourses. As scholars concerned with the lack of diverse resources in contemporary conversations about ethics, we should celebrate Confucian role ethics and other interpretations of non-western traditions that are finding a home and a place to grow and develop in contemporary ethical discourse and as resources for enriching how we might live well together.

\section{NOTES}

1. Stephen Angle, "The Analects and Moral Theory," in Dao Companion to the Analects, ed. Amy Olberding (New York: Springer Press, 2014), 225.

2. Roger Ames, Confucian Role Ethics: A Vocabulary (Honolulu: University of Hawai'i Press, 2011), 2.

3. Kam-Por Yu, Julia Tao, and Philip J. Ivanhoe, "Why Take Confucian Ethics Seriously," in Taking Confucian Ethics Seriously: Contemporary Theories and Applications (Albany, NY: SUNY Press, 2011), 1.

4. As far as I am able to ascertain, the first use of the phrase Confucian Role Ethics is in a dissertation, "An Ethic of Loving: Ethical Particularism and the Engaged Perspective in Confucian Role-Ethics," by Sin Yee Chan, out of the University of Michigan in 1993. However, this does not appear connected to the later use of the term by Ames and Rosemont. Angle describes the first use of this by them in print in 2009, although earlier references exist to "role-bearing persons" in Confucian ethics by Ames and Rosemont (Angle, 2014). Also, apparently unconnected, A.T. Nuyen has published on Confucian Role Ethics (2007), although, again, not meaning the same thing as Ames and Rosemont. And, while Zhang Dongsun did not use the phrase "Confucian Role Ethics" there is clearly a significant similarity in content between his work and Ames and Rosemont's, and this is a debt they acknowledge.

5. Sarah Mattice, "Confucian Role Ethics in the 21st Century: Domestic Violence, Same-sex Marriage, and Christian Family Values," in Feminist Encounters with Confucius, eds. Sor-hoon Tan and Mathew Foust (Leiden: Brill, 2016).

6. I say here "Confucian traditions" because Confucianism is not a monolithic tradition, but admits of much variety and difference across historical periods and geographical locations.

7. Ames 2011, 85.

8. Analects 12.11 .

9. Sarah Mattice, “On 'Rectifying' Rectification: Reconsidering Zhengming in Light of Confucian Role Ethics," Asian Philosophy, 20.3 (2010): 247-60, 254.

10. Analects 13.3, my translation and paraphrase.

11. Mattice 2010, 257.

12. Ames 2011, 98.

13. For more on this from Zhang, see Xinyan Jiang's "Pluralist Epistemology and Chinese Philosophy", p. 29, and Zhang, Knoweldge and Culture (Shanghai: 
Commercial Press 1946), 75. Zhang specifically used the phrase "metaphysics" to refer to doctrines asserting the existence and primacy of substance.

14. Lawrence Venuti, The Translator's Invisibility: A History of Translation (New York: Routledge Press, 2008), 24, 34, 36. To be clear, to my knowledge neither Ames nor any of the other proponents of CRE use Venuti or this kind of argument to justify the project.

15. Venuti 2008, 1.

16. Venuti himself is primarily focused on literature, but there is no reason his comments here could not also apply to philosophical works.

17. Venuti 2008, 17.

18. Ibid., 19-20.

19. Ibid., 20.

20. Ibid., 42.

21. Ibid., 41.

22. Ames 2011, xvi, paraphrasing from Henry Rosemont Jr.'s 1991 chapter, "Rights-bearing Individuals and Role-bearing Persons" in Rules, Rituals, and Responsibility: Chapters Dedicated to Herbert Fingarette, ed. Mary I. Bockover (La Salle, IL: Open Court Press, 1991).

23. Ames 2011, 73, 128-34.

24. Phillip Lewis, "The Measure of Translation Effects," in Difference in Translation, ed. J. Graham, 1985, quoted in Venuti 2008, 24.

25. See for instance Ames 2011, 171 and 189.

26. To be clear, this doesn't mean that projects attempting to draw out similarities between Confucian ethics and a Western ethical tradition are necessarily ethnocentric.

27. This is true of part of the value of a translation, but it is not the entirety of value. Other translation standards are still relevant, and this does not imply that anything goes, or that translations do not need to be anchored in texts and time periods.

28. Jean Grondin, The Philosophy of Gadamer, trans. Kathryn Plant (Ithaca: McGill-Queen's University Press, 2003), 84.

29. Again, this differs from other interpretive projects due in part to purpose. For instance, in Bryan Van Norden's Virtue Ethics and Consequentialism in Early Chinese Philosophy (2012), instead of trying to articulate ambient cultural assumptions, he is focused explicitly on drawing out arguments from the text.

30. Although not much of his work is available in translation, see Jiang 2014 for a translation of selected works and a commentary chapter on Zhang.

31. Contemporary China and Mandarin Chinese are also, in a sense, another language and context, also clearly closer in many regards than English and contemporary America as cultural contexts.

32. See chapter two of Confucian Role Ethics: A Vocabulary for a discussion of correlative cosmology as it relates to the Yijing, to Traditional Chinese 
Medicine, and to the work of Tang Junyi. See chapter three of Confucian Role Ethics: A Vocabulary, for a discussion of relational personhood, especially III.13.

33. For an excellent discussion of what this means, without the language of "relational personhood," see the end of chapter two of Yong Huang's Why Be Moral, 2014.

34. Many of these ideas can be found in Zhang's work, although not under the name "Confucian Role Ethics."

35. Ames 2011, 72.

36. For more on this idea of asymmetry, see Kwong Loi-Shun's chapter, "Studying Confucian and Comparative Ethics: Methodological Reflections" in the Journal of Chinese Philosophy 36 (3): 455-78 (2009).

37. Chenyang Li, "Capacities and Purposes of Comparative Philosophy," special panel on How to Do Chinese and Comparative Philosophy I: Methodology, ACPA, APA Eastern Division Meeting, January 2016.

38. See Ames 2011, 20-35.

39. Many contemporary theorists have slightly different accounts of what these analogies look like. For instance, Aaron Stalnaker calls them "bridge concepts" and argues that they can form loose focal points for comparative work. See Aaron Stalnaker Overcoming Our Evil: Human Nature and Spiritual Exercises in Xunzi and Augustine (Washington DC: Georgetown University Press), 2006.

40. Aaron Creller, "De-Orienting Comparative Philosophy: Approaching the 'West' From China,' presented at the APA Eastern Division Meeting, January 2016.

41. Ames 2011, 32.

42. Stalnaker 2006, 15-16; Shun 2009, 267-8.

43. Leah Kalmanson, "Annotating the Self: The Ritual Methods of Comparative Philosophy," Philosophy East and West Vol. 67, No. 3 (2017).

\section{WORKS CITED}

Ames, Roger. Confucian Role Ethics: A Vocabulary. Honolulu: University of Hawai'i Press, 2011.

Angle, Stephen. "The Analects and Moral Theory," in Dao Companion to the Analects, ed. Amy Olberding. New York: Springer Press, 2014.

Bell, Daniel. "A Comment on Confucian Role Ethics," in Frontiers of Philosophy in China 7.4 (2012): 626-31.

Grondin, Jean. The Philosophy of Gadamer, trans. Kathryn Plant. Ithaca: McGillQueen's University Press, 2003.

Jiang, Xinyan. "Pluralist Epistemology and Chinese Philosophy," in Knowledge, Culture, and Chinese Philosophy: A Study and Translation of Zhang Dongsun's Works. New York: Global Scholarly Publications, 2014.

Kalmanson, Leah. "Annotating the Self: The Ritual Methods of Comparative Philosophy." Philosophy East and West 67.3 (2017). 
Huang, Yong. Why Be Moral? Learning from the Neo-Confucian Cheng Brothers. Albany, NY: SUNY Press, 2014.

Li, Chenyang. "The Confucian Concept of Jen and the Feminist Ethics of Care: A Comparative Study" in Hypatia 9.1 (1994): 70-89.

Mattice, Sarah. "Confucian Ethics in the Twenty-First Century", Frontiers of Philosophy in China, 7.4 (2012): 632-7.

Mattice, Sarah. "Confucian Role Ethics in the 21st Century: Domestic Violence, Same-sex Marriage, and Christian Family Values," in Feminist Encounters with Confucius. Ed. Sor-hoon Tan and Mathew Foust. Brill Press, 2016.

Mattice, Sarah. "On 'Rectifying' Rectification: Reconsidering Zhengming in Light of Confucian Role Ethics," Asian Philosophy 20.3 (2010): 247-60.

Nuyen, A.T. "Moral Obligation and Moral Motivation in Confucian Role-Based Ethics." Dao: A Journal of Comparative Philosophy 8.1 (2009): 1-11.

Ramsey, John. "The Role Dilemma in Early Confucianism." Frontiers of Philosophy in China 8.3 (2013): 376-87.

Rosemont, Henry Jr. "Rights-bearing Individuals and Role-bearing Persons" in Rules, Rituals, and Responsibility: Chapters Dedicated to Herbert Fingarette, ed. Mary I. Bockover, La Salle, IL: Open Court Press, 1991.

Shun, Kwong Loi. "Studying Confucian and Comparative Ethics: Methodological Reflections" in the Journal of Chinese Philosophy 36.3 (2009):455-78.

Sim, May. "Review of Roger Ames' Confucian Role Ethics," Frontiers of Philosophy in China, 7.4 (2012): 638-43.

Stalnaker, Aaron. Overcoming Our Evil: Human Nature and Spiritual Exercises in Xunzi and Augustine, Washington DC: Georgetown University Press, 2006.

Van Norden, Bryan. Virtue Ethics and Consequentialism in Early Chinese Philosophy. Cambridge: Cambridge University Press, 2012.

Yu, Kam-Por, Julia Tao, and Philip J. Ivanhoe, "Why Take Confucian Ethics Seriously," Taking Confucian Ethics Seriously: Contemporary Theories and Applications. Albany, NY: SUNY Press, 2011.

Venuti, Lawrence. The Translator's Invisibility: A History of Translation. New York: Routledge Press, 2008.

Wen Haiming. "Confucian Role Ethics in Chinese- and English-Language Contexts," Frontiers of Philosophy in China, 7.4 (2012): 649-56.

Zhang Dongsun. Zhishi yu Wenhua 知識與文化 (Knowledge and Culture), Shanghai: Commercial Press, 1946.

Zhang Xiaolong. "Time in Familial Reverence-Deference (孝): A Comment on Roger T. Ames' Confucian Role Ethics", Frontiers of Philosophy in China, 7.4 (2012): 657-61. 